\title{
NUMERICAL SOLUTION OF COMPRESSIBLE STEADY FLOWS IN A 2D GAMM CHANNEL AND DCA 18\% PROFILE
}

\author{
Pavel KRYŠTU゚FEK, Karel KOZEL` \\ Abstract: The article presents results of a numerical solution of subsonic and \\ transonic flows described by the system of Euler equations in $2 D$ flows in a \\ channel and around a profile. Authors used Lax-Wendroff scheme to numerically \\ solve the flows in a GAMM channel and around half DCA $18 \%$ profile. Authors \\ programmed the mesh generator of the type $C$ for profile with a blunt leading edge.
}

\section{INTRODUCTION}

A numerical code has been developed for simulating transonic flow field in GAMM channel and around half DCA $18 \%$ profiles. For future simulating mesh generator type $\mathrm{C}$ has been developed. In this case mesh has been created for numerical solution over profile NACA 0012.

\section{Mathematical models}

The 2D flow of an inviscid compressible fluid is described by the system of Euler equations.

$$
W_{t}+F(W)_{x}+G(W)_{y}=0
$$

where

$$
\begin{gathered}
W=\left[\begin{array}{c}
\rho \\
\rho w_{1} \\
\rho w_{2} \\
e
\end{array}\right], F(W)=\left[\begin{array}{c}
\rho w_{1} \\
\rho w_{1}^{2}+p \\
\rho w_{1} w_{2} \\
(e+p) w_{1}
\end{array}\right], G(W)=\left[\begin{array}{c}
\rho w_{2} \\
\rho w_{1} w_{2} \\
\rho w_{2}^{2}+p \\
(e+p) w_{2}
\end{array}\right], \\
p=(\kappa-1)\left[e-\frac{1}{2} \rho\left(w_{1}^{2}+w_{2}^{2}\right)\right] .
\end{gathered}
$$

In the above equations, $W$ is conservative variable, $F, G$ are function of inviscid physical fluxes, $\rho$ denotes density, $w_{1}, w_{2}$ are components of velocity in the direction of axis $x, y, p$ is pressure, $e$ is total energy per unit volume. The parameter $\kappa=1.4$ is the adiabatic exponent.

\section{Specification OF TeSt CASES}

We selected for numerical solution a structured mesh formed by quadrilateral finite volumes. Mesh for GAMM channel with selecting parameters is presented in Fig. 1. Mesh with half DCA $18 \%$ profile with selecting parameters is presented in Fig. 2. A program for generating mesh makes it possible any thickening of mesh in $x$ direction. In $y$ direction is controlled density only one parameter.

\footnotetext{
- Ing. Pavel Kryštůfek, Czech Technical University of Liberec, Faculty of Mechanical Engineering, Dept. of Power Engineering Equipment, Studentská 2, 46117 Liberec 1, pavel.krystufek@tul.cz prof. RNDr. Karel KOZEL DrSc., Czech Technical University in Prague, Faculty of Mechanical Engineering, Karlovo náměstí 13, 12135 Prague 2; karel.kozel@fs.cvut.cz
} 


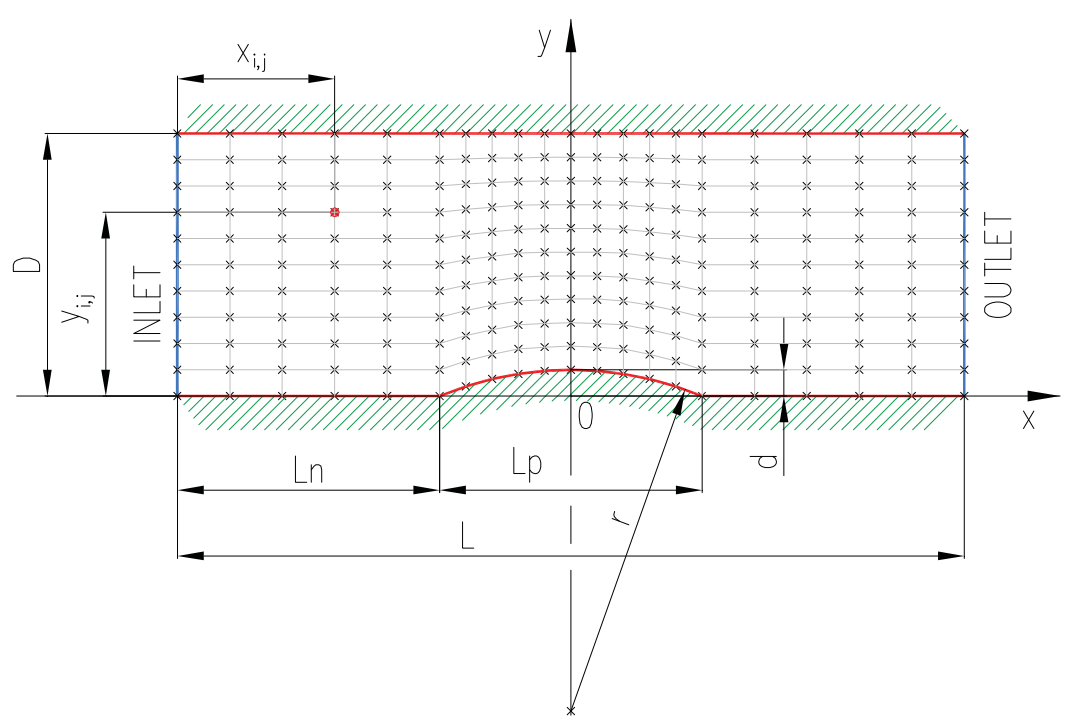

Figure 1: Structured mesh formed quadrilateral elements for GAMM channel

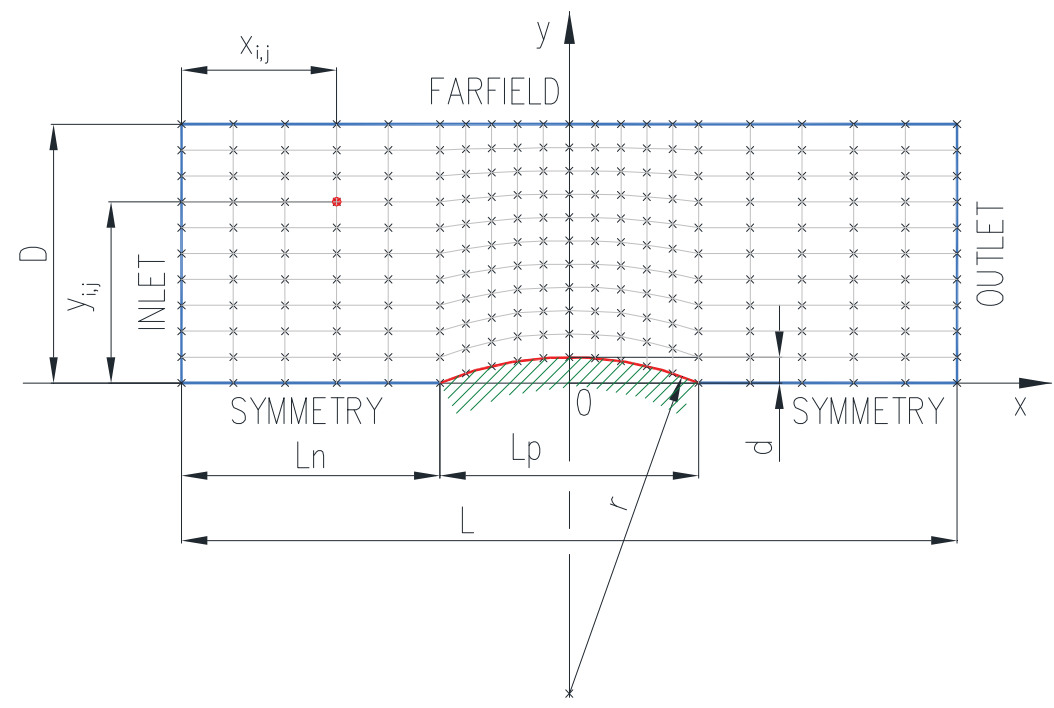

Figure 2: Structured mesh formed quadrilateral elements for half DCA $18 \%$ profile

\section{NUMERICAL METHOD}

Lax-Wendroff scheme in McCormack's modification (LW-MC) of the finite volume method is used on non-orthogonal structured grids of quadrilateral cells $D_{i j}$. In predictor part author used forward differencing and in corrector part backward differencing.

Predictor:

$$
W_{i, j}^{n+1 / 2}=W_{i, j}^{n}-\frac{\Delta t}{\mu_{i, j}} \sum_{k=1}^{4}\left(\tilde{F}_{k}^{n} \Delta y_{k}-\tilde{G}_{k}^{n} \Delta x_{k}\right)
$$


Corrector:

$$
W_{i, j}^{n+1}=\frac{1}{2}\left(W_{i, j}^{n}+W_{i, j}^{n+1 / 2}-\frac{\Delta t}{\mu_{i, j}} \sum_{k=1}^{4}\left(\tilde{F}_{k}^{n+1 / 2} \Delta y_{k}-\tilde{G}_{k}^{n+1 / 2} \Delta x_{k}\right)\right)+A D\left(W_{i, j}^{n}\right)
$$

The Jameson's artificial dissipation $A D$ damps undesirable oscillations and improves the stability of the method

$$
\begin{gathered}
A D\left(W_{i, j}^{n}\right)=k_{1} \gamma_{i}\left(W_{i+1, j}^{n}-2 W_{i, j}^{n}+W_{i-1, j}^{n}\right)+k_{2} \gamma_{j}\left(W_{i, j+1}^{n}-2 W_{i, j}^{n}+W_{i, j-1}^{n}\right) \\
\gamma_{i}=\frac{\left|p_{i+1, j}^{n}-2 p_{i, j}^{n}+p_{i-1, j}^{n}\right|}{\left|p_{i+1, j}^{n}\right|+2\left|p_{i, j}^{n}\right|+\left|p_{i-1, j}^{n}\right|}, \gamma_{j}=\frac{\left|p_{i, j+1}^{n}-2 p_{i, j}^{n}+p_{i, j-1}^{n}\right|}{\left|p_{i, j+1}^{n}\right|+2\left|p_{i, j}^{n}\right|+\left|p_{i, j-1}^{n}\right|}
\end{gathered}
$$

The convergence to the steady state is followed by log L2 residual defined by

$$
\operatorname{Re} z W_{i, j}^{n}=\frac{1}{N} \sqrt{\sum_{i, j}\left(\frac{W_{i, j}^{n+1}-W_{i, j}^{n}}{\Delta t}\right)^{2}}
$$

where $\mathrm{N}$ is a number of all elements in the computational domain.

At inlet part set values are considered for flow at infinity. At outlet $p$ is given and other values are extrapolated. On wall zero derivatives of velocity vector along normal is considered.

$$
\frac{\delta \mathbf{w}}{\delta \mathbf{n}}=0
$$

The initial conditions must agree with request of even input approaching flow. That was defined by Mach number $\mathrm{Ma}$, size of density and absolute size of velocity, where $\alpha$ is an angle between centers neighboring cells in $x$ direction.

$$
W=\left[\begin{array}{c}
1 \\
M a \cdot \cos (\alpha) \\
M a \cdot \sin (\alpha) \\
\frac{1}{\kappa(\kappa-1)}+\frac{1}{2} M a^{2}
\end{array}\right]
$$

\section{Numerical RESULtS}

For a 2D numerical simulation of flows of an inviscid compressible fluid in the GAMM channel and around half DCA $18 \%$ profile, the authors applied $\mathbf{L W}$ numerical schemes in McCormack's modification on a structured grid with $400 \times 200$ cells.

In the case of GAMM channel results (Fig. 3) are in very good agreement with the results from the author Fürst, 2004 [12] (Fig. 4) with computational grid $90 \times 30$ cells. Positions of the shock wave (with an obvious of Zierep singularity) are the same. The maximum Mach number in our case is higher than [12] $\left(M_{\max }=1.4298 \times M_{\max }=1.33\right)$.

In the case of half DCA $18 \%$ profile results are shown on Fig 5 and Fig.6. The result of pressure coefficient $C_{p}$ (Fig. 6) is compared with G. S. Deiwert obtained by finitediference method with computational grid $50 \times 38$ cells. Progress of the pressure coefficient $C_{p}$ for inviscid flow from Deiwert is coarser and does not show details that are visible in our results. 

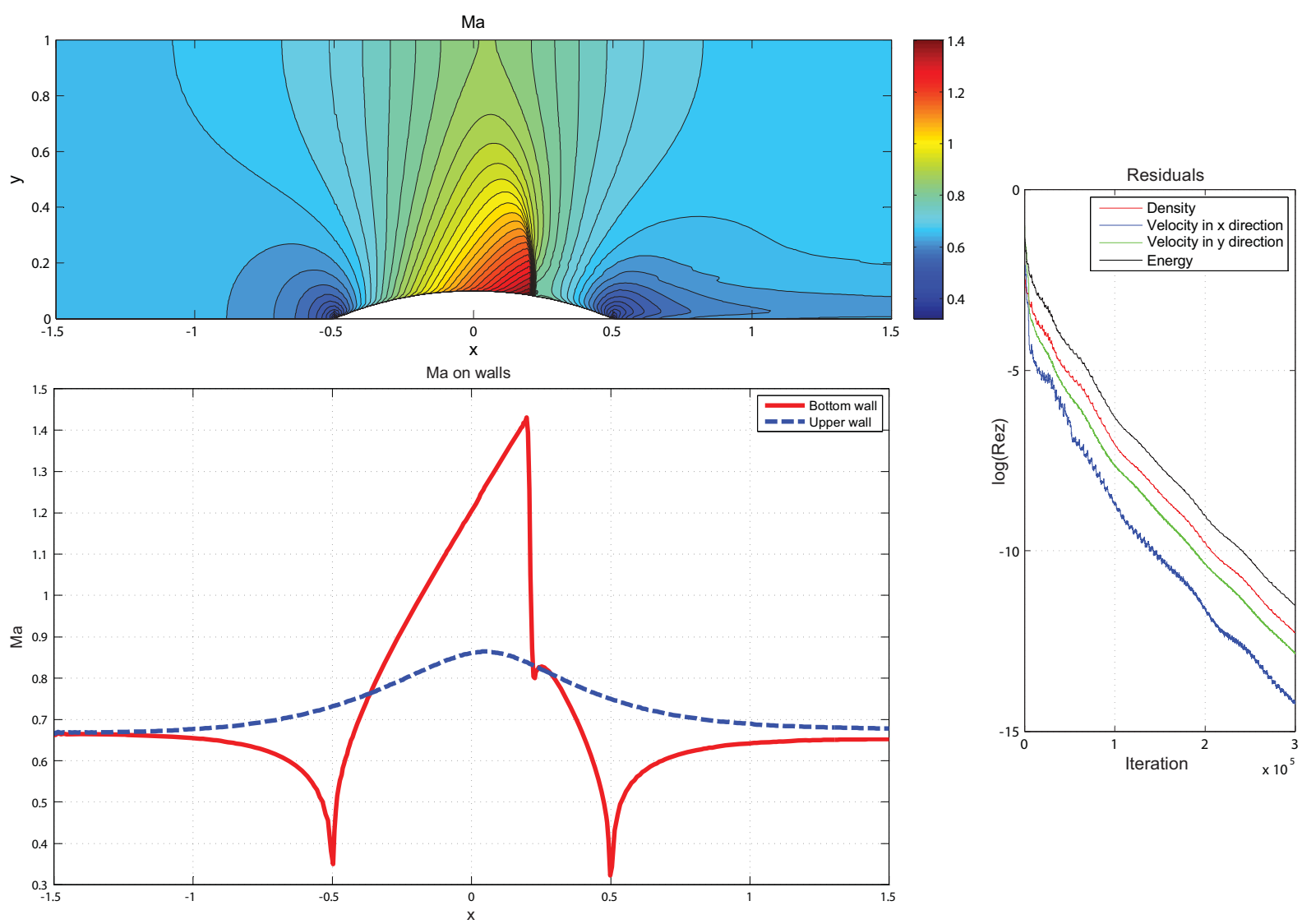

Figure 3: Inviscid compressible flow in the GAMM channel: Mach number isolines (top) and Mach number on bottom and upper wall (bottom) and $L_{2}$ logarithmic residuals (right) at $M a=0.675$ LW-MC scheme, $M_{\max }=1.4298$, structured grid with $400 \times 200$ elements.

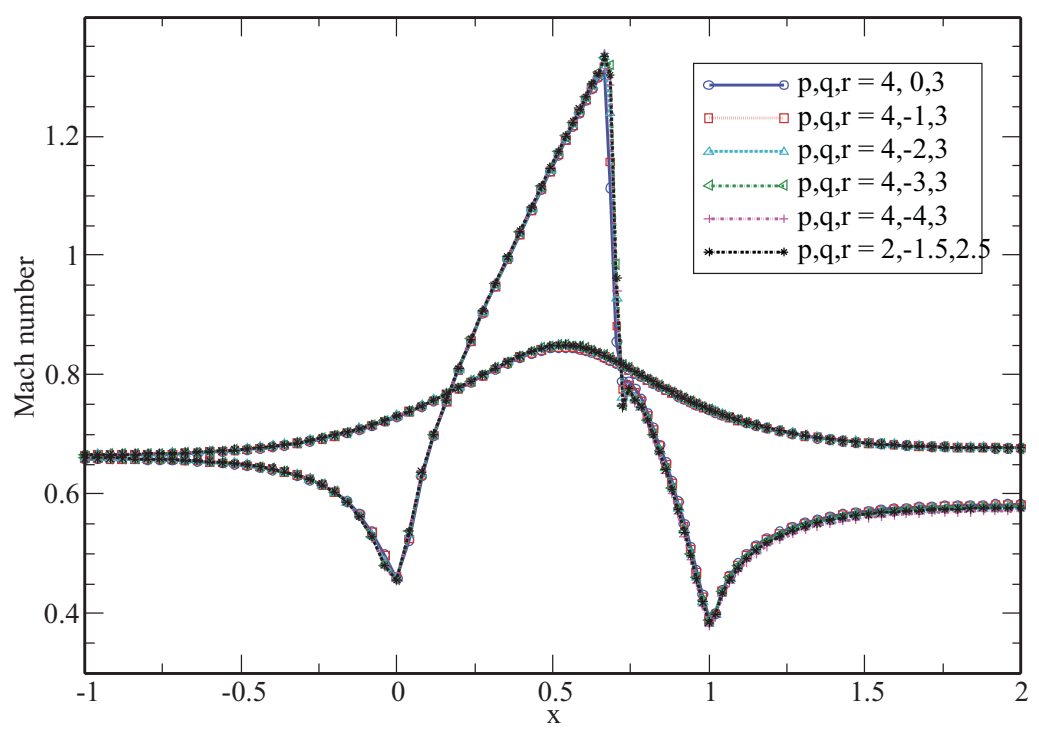

Figure 4: Inviscid compressible flow in the GAMM channel: Mach number on bottom and upper wall - Fürst, 2004 [12] 

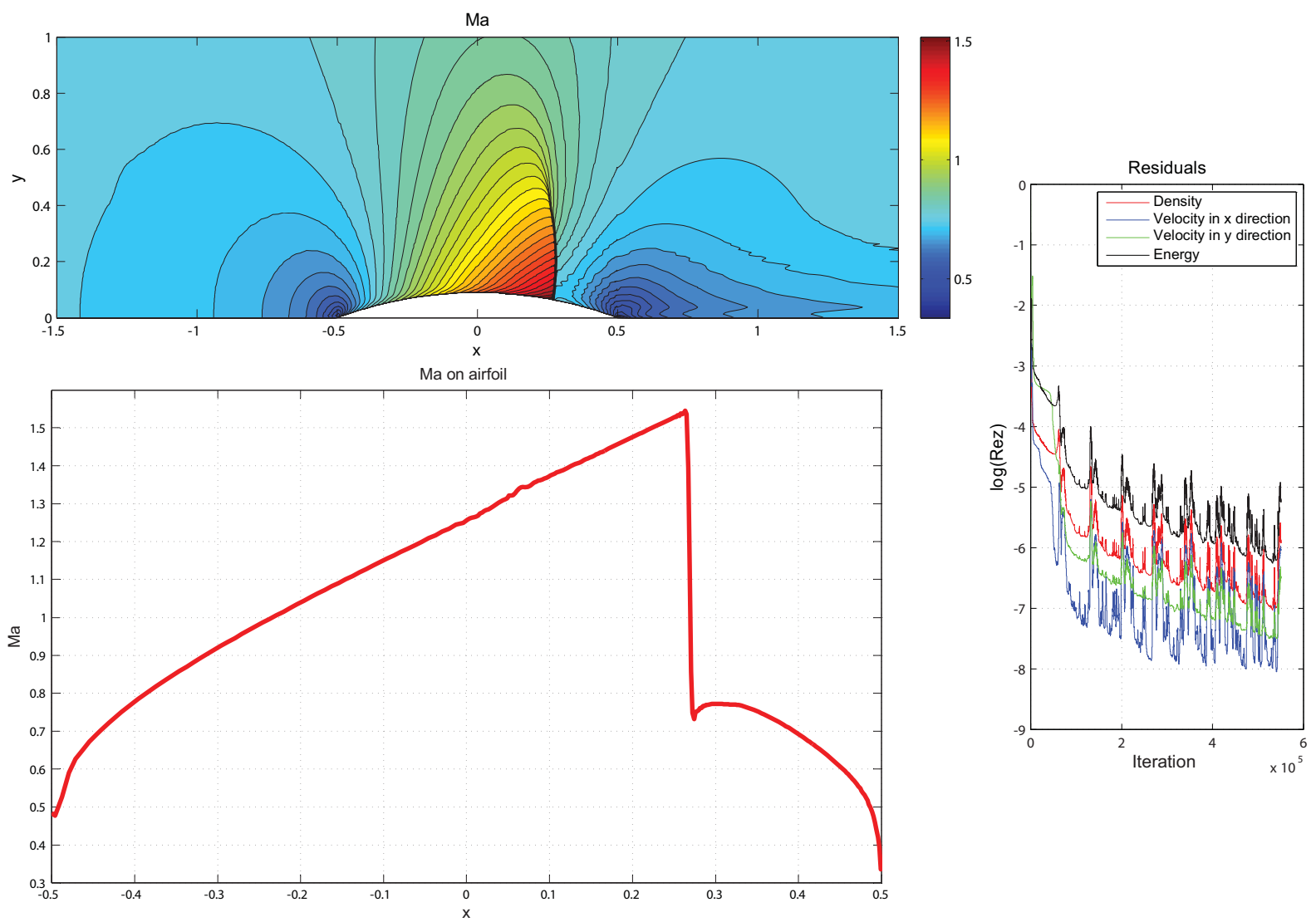

Figure 5: Inviscid compressible flow around half DCA 18\% airfoil: Mach number isolines (top) and Mach number on upper airfoil (bottom) and $L_{2}$ logarithmic residuals (right) at $M a=0.775 L W-M C$ scheme, $M_{\max }=1.5453$, structured grid with 400x200 elements.
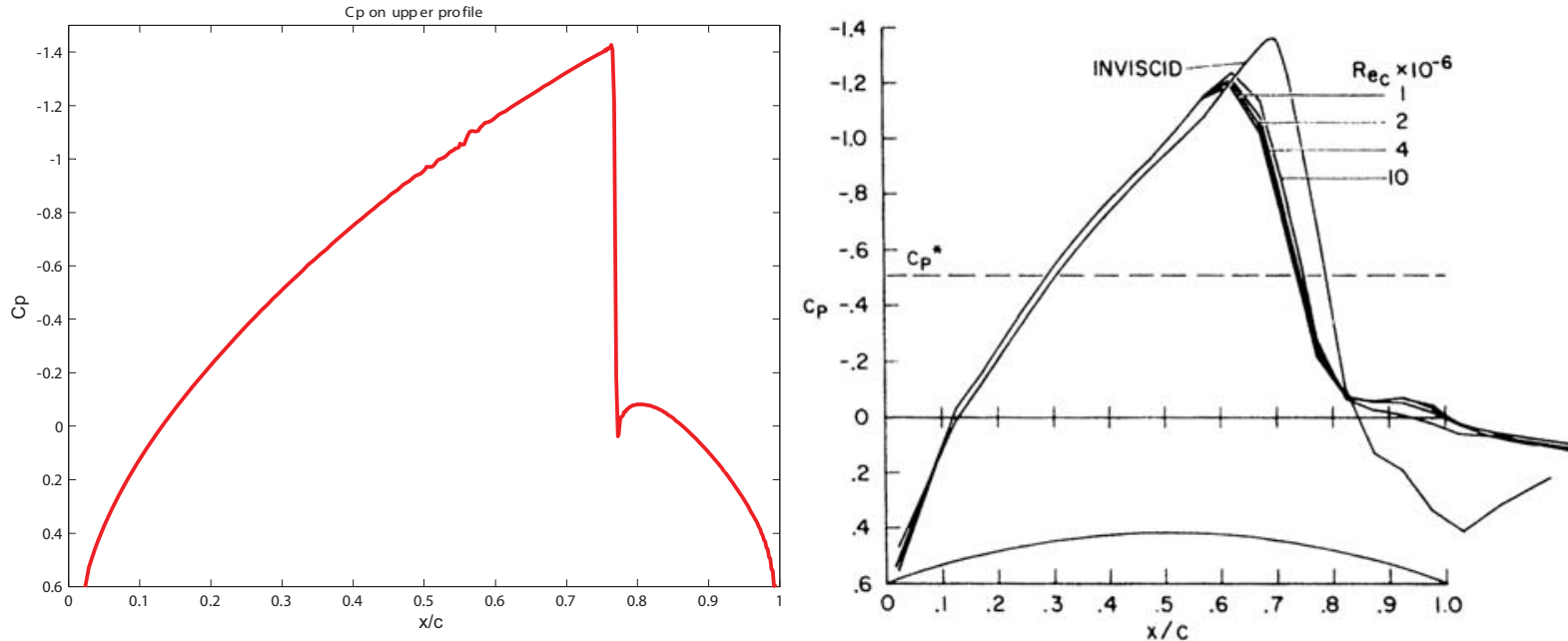

Figure 6: Pressure distribution over DCA 18\% (left) - Deiwert, 1975 [7] (right) 


\section{Meshes PREPARATION OF PROFILES With A BLUNT LEADING EDgE}

The grid around profiles (wing) usually consists of a C-grid in the flow direction (Fig. 7.).

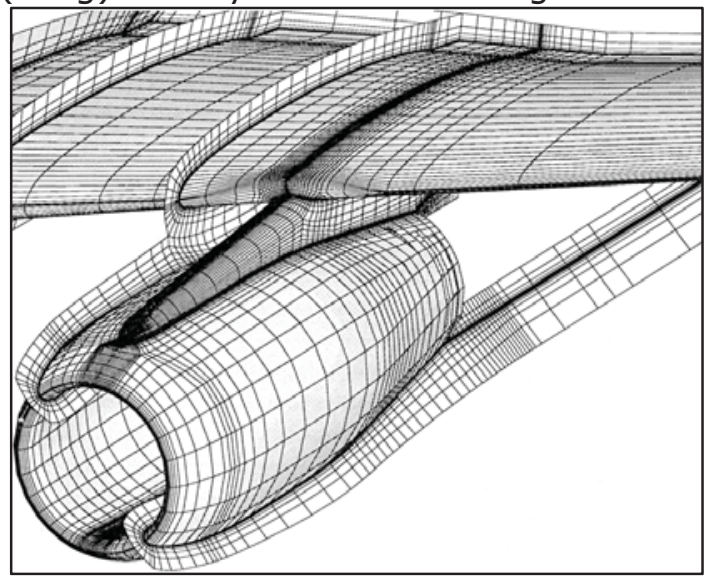

Figure 7: Structured surface and volume grid of a wing-body configuration (Courtesy $O$. Brodersen, DLR, Germany)

In the case of the C-topology (Fig. 7.) the aerodynamics body is enclosed by one family grid lines, which also form the wake region. The situation is sketched in Fig. 8.

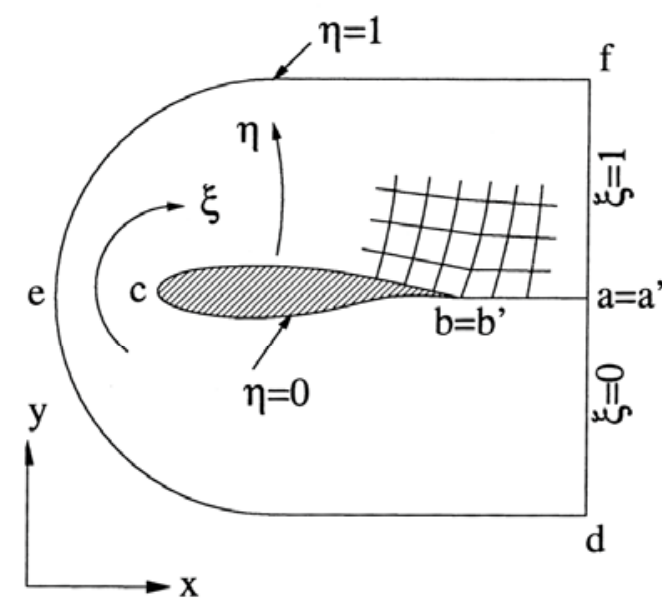

(a) physical space

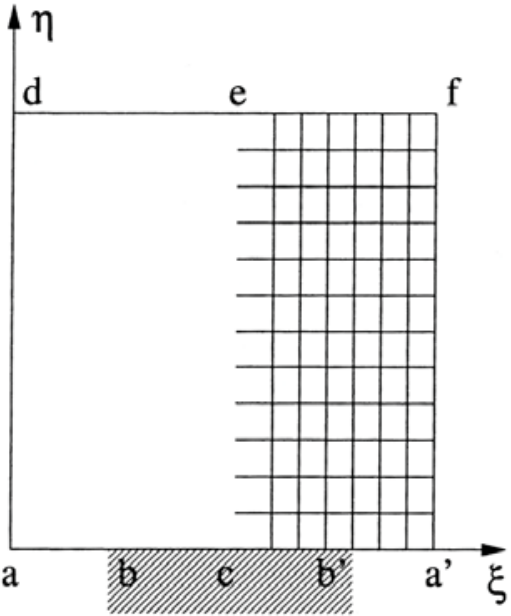

(b) computational space

Figure 8: C-grid topology in 2D (by Blazek [8])

The initial grid is generated algebraically by using the linear TFI method [8 - pg. 382], [9]. Afterwards, elliptic PDE's are employed to produce boundary-orthogonal grid with specific wall spacing. The NACA0012 airfoil contour is approximated by a Bezier spline [8 - pg. 384], [10], [11].

Examples of grid created by ours program were presented in Fig. 9. 


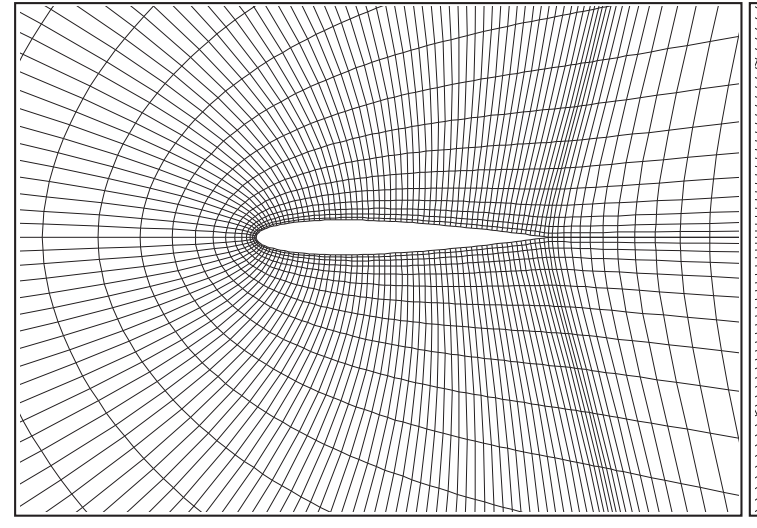

Inviscid, C-type - NACA 0012 airfoil

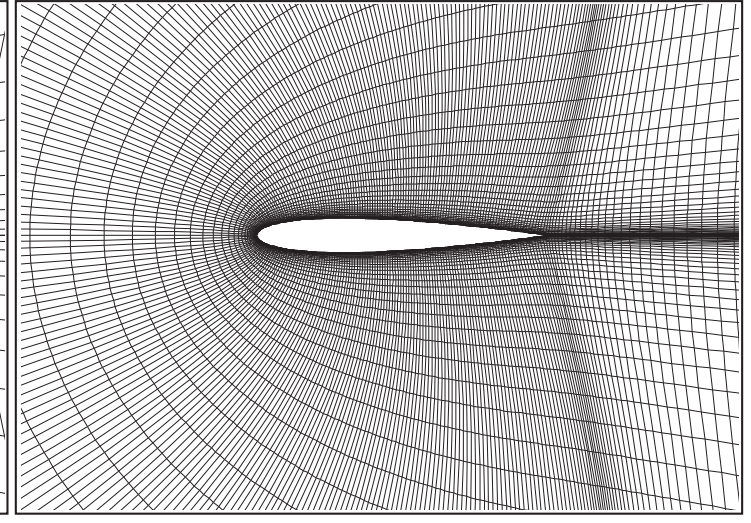

Viscid, C-type - NACA 0012 airfoil

Figure 9: Inviscid a viscid C-type mesh of NACA 0012 airfoil

\section{CONCLUSIONS}

Numerical solution has been applied on structured meshes with $400 \times 200$ elements. The LW-MC sheme has been used for GAMM channel and half DCA $18 \%$ airfoil. Then results were compared with other authors [7], [12]. The mesh generator of the type C for profile with a blunt leading edge has been programed.

\section{ACKNOWLEDGMENTS}

The work was partly supported by the grant project SGS2823 and Research Plan MSMT 6840770010 .

\section{REFERENCES}

[1] Kryštůfek, P. - Kozel, K.: Numerical solution of compressible steady flows in a 2D channel, Experimental fluid mechanics 2007, 2007, pg 71

[2] Kryštůfek, P. - Kozel, K.: Numerical solution of compressible steady flows in a channel, TUL, Liberec 2004

[3] Dvořák, R. - Kozel, K.: Matematické modelování v aerodynamice, ČVUT, Praha 1996

[4] Kozel, K. - Fürst, J.: Numerické metody řešení problému proudění I, ČVUT, Praha 2001

[5] White, Frank M.: Fluid Mechanics - Fourth Edition, McGraw-Hill, 2001

[6] Fořt, J. - Jirásek, A. - Kozel, K.: Numerical solution of the inviscid flow over a profile, Letecký zpravodaj 1/1998

[7] Deiwert, G.S.: High Reynolds number transonic flow simulation, Proceedings of the Fourth International Conference on Numerical Methods in Fluid Dynamics, 1975, pg 132

[8] Blazek, J. - Computational Fluid Dynamics: Principles and Applications, Elsevier, 2005

[9] Vierendeels, J. - Riemslagh, K. - Dick, E.: Flow Calculation in Complex Shaped Moving Domains, AIAA Paper 97-2044, 1997

[10] Sommerfeld, A.J.W.: Partial Differential Equations in Physics, Academie, New York, 1949

[11] Courant, R. - Hilbert, D.: Methods of Mathematical Physics, Interscience, New York, 1962

[12] Fürst, J.: Numerical solution of inviscid and viscous flows using modern schmes and quadrilateral or triangular mesh, Proceedings of the Czech-Japanese Seminar in Applied Mathematics 2004, Czech Technical University in Prague, August 4-7, 2004 